\title{
Dimensional Latent Structure of Callous-Unemotional Traits in German Adolescents: Results from Taxometric Analyses
}

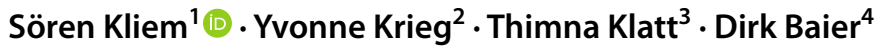

Accepted: 3 November 2021 / Published online: 13 November 2021

(c) The Author(s) 2021

\begin{abstract}
A large amount of research has addressed the issue of the latent status of psychiatric disorders and related phenomena. We used a new taxometric approach developed by Ruscio to examine the latent status of callous-unemotional (CU) traits in a large representative study of German ninth graders $(N=3,878)$. Rather than estimating a putative taxon base rate and using that estimate to generate the taxon comparative data, we estimated CCFI profiles with each base rate estimate between $2.5 \%$ and $97.5 \%$ in increments of $2.5 \%$. Results of different indicator sets clearly suggested a dimensional solution. This finding is consistent with different studies showing the dimensionality of psychopathy in adolescents. In summary, the results of this study point to the need for critical reflection in defining a high-risk-group in the context of CU traits. However, further studies are necessary to substantiate this result in different samples using different measurement approaches.
\end{abstract}

Keywords Callous Unemotional Traits (CU traits) $\cdot$ Psychopathy $\cdot$ Taxometrics $\cdot$ Latent Structure $\cdot$ Assessment

Callous-unemotional (CU) traits have been found to be closely related to the affective dimension of psychopathy (Hare \& Neumann, 2008; Kimonis et al., 2015). Different authors argue that $\mathrm{CU}$ traits are useful for identifying a highrisk group $(\mathrm{CU}+)$ within children with Conduct Disorder (CD; Frick \& White, 2008). This group is characterized by marked differences in neurocognitive, emotional, and behavioral functioning, including lower autonomic responsiveness to empathy-inducing stimuli (Frick, \& Viding, 2009; de

Sören Kliem

Soeren.kliem@eah-jena.de

Yvonne Krieg

Yvonne.krieg@kfn.de

Thimna Klatt

thimna.klatt@hspv.nrw.de

Dirk Baier

baid@zhaw.ch

1 Ernst-Abbe-Hochschule Jena - University of Applied Sciences, Carl-Zeiss-Promenade 2, 07745 Jena, Germany

2 Criminological Research Institute of Lower Saxony, Hannover, Germany

3 University of Applied Sciences for Police and Public Administration in North Rhine-Westphalia, Hagen, Germany

4 Zurich University of Applied Sciences, Zürich, Switzerland
Wied et al., 2012), disturbances in affective theory of mind (Sebastian et al., 2012), lower sensitivity to punishment (Frick et al., 2014), and changes in brain regions involved in emotion and learning (e.g., amygdala, Blair et al., 2014). Collectively, these characteristics are assumed to contribute to the more violent, chronic, and recidivist pattern of antisocial behavior exhibited by youth with high CU traits and are an important target for intervention (Cecil et al., 2018). Furthermore, it has been demonstrated that treatment nonresponders have significantly higher $\mathrm{CU}$ levels than responders (e.g., Falkenbach et al., 2003; Gretton et al., 2001; Hawes \& Dadds, 2005; Masi et al., 2013; O'Neill et al., 2003; Spain et al., 2004; Waschbusch et al., 2007). Moreover, CU traits in school-aged children predict later criminal and antisocial behavior in adulthood, even after controlling for CD severity and onset (McMahon et al., 2010).

For these reasons, the DSM-5 revisions (American Psychiatric Association, 2013) added the possibility of additional coding (descriptive features specifier) "with Limited Prosocial Emotions" (LPE) to the CD diagnosis. To warrant this additional coding, at least two of the four specifiers must occur within the same time period and across different relationships and situations: (a) lack of remorse or guilt; (b) callous lack of empathy; (c) unconcerned about performance; (d) shallow or deficient affect. These four criteria closely approximate the affective dimension of psychopathy in adult 
samples (Hare \& Neumann, 2008). Accordingly, the DSM-5 follows a categorical conceptualization (with specifier [high risk] vs. without specifier) of CU traits.

\section{Latent Structure of CU Traits}

In addition to conceptualizing $\mathrm{CU}$ traits as categorical (i.e., identifying high-risk individuals who score above a certain cut-off value), they can also be understood as forming a latent continuum. A number of studies have been conducted to investigate if certain psychiatric disorders consist of discrete categories of behaviors, or if they rather form a continuum connecting extreme forms of behavioral traits on a single dimension (Haslam et al., 2020). The issue of whether a phenomenon (e.g., a mental disorder) is appropriately conceptualized as "dimensional" (i.e., as manifestations along a continuum of behavioral characteristics) or as discrete categorical entities has important implications for research, theory, and practice (Ruscio \& Ruscio, 2004). For example, the latent status of a construct is important for the classification of individuals. If the underlying construct is continuous, the convention for classification into dichotomous groups (e.g., treatment vs. no treatment) must be derived based on certain criteria that are not part of the diagnosis (external validation criteria). If, on the other hand, a true categorical latent structure is present, providing clinically relevant cut-off values to differentiate the corresponding groups appears to be an essential target. Furthermore, identifying the latent structure of a phenomenon is also important to guide research into its etiopathogenesis (i.e., the cause and development of an atypical condition or disease). It can be argued that a dimensional structure is rather generated by a multitude of different risk factors through addition and interaction. On the other hand, existence of categorical latent structure can result from a specific etiology or developmental bifurcation (see Meehl, 1995; Ruscio et al., 2006). Moreover, in the context of prognostic studies (i.e., using CU traits as an explanatory factor) or studies on etiological factors (i.e., CU traits as the outcome), the latent status of a phenomenon seems to be of particular importance and should influence the selection of the appropriate statistical procedures.

To determine whether the latent structure of a construct is best conceptualized as dimensional or categorical, taxometric methods are often used. Taxometric techniques were originally discussed by Paul E. Meehl to test his conjecture that a discrete latent variable ("taxon") underlies vulnerability to schizophrenia (Golden \& Meehl, 1979). Meehl (1995) introduced a fundamental feature into modern taxometric analyses. Several nonredundant data-analytic procedures (see Ruscio et al., 2011 for a detailed description) are applied and the final interpretation of the latent structure of the construct are based on the convergence among these procedures.

A significant methodological development in taxometric analysis represents the introduction of a systematized approach to taxometric inference by Ruscio et al. (2007). These authors developed a procedure in which taxometric plots based on observed data are compared with plots from parallel analyses of matched (e.g., sample size, marginal distributions, correlation matrix) simulated comparison datasets generated from a population of data using a taxonomic or dimensional latent structural model. In addition, the authors developed an index (Comparison Curve Fit Index, CCFI) which quantifies the similarity of the observed curves from the simulated curves. A CCFI value $<0.45$ indicates a dimensional structure, a CCFI value of $>0.55$ indicates a categorical structure. Values between 0.45 and 0.55 are considered ambiguous. The CCFI value can be calculated independently for the different taxometric procedures. A final interpretation is then usually based on a mean CCFI value (Ruscio et al., 2018). This method of simulated comparative data set and the use of CCFI have become almost universally accepted (Haslam et al., 2020).

A number of previous taxometric studies consistently support the dimensionality of psychopathy in adolescents (Edens et al., 2011; Murrie et al., 2007; Vasey et al., 2005; Walters, 2014). However, to the authors' best knowledge only one study has examined the latent structure of CU traits so far. Herpers et al. (2017) analyzed the data of $N=979$ Dutch children and adolescents using taxometric analysis. The results of their study, namely the Comparison Curve Fit Index (CCFI; Ruscio et al., 2007), point to a dimensional latent structure of CU traits. However, a number of limitations apply to the Herpers et al. study. The authors did not provide any information on what type of indicator they used and whether the requirements for the analysis were met (i.e., within-group correlations, indicator validity, number of indicators, number of ordered categories). In addition, the estimated baseline prevalence of the possible taxon subgroup, the estimation method and subgroup analyses (e. g. regarding gender) were not provided. In the present study, we replicate the taxometric analysis of CU traits, avoiding the limitations of the study by Herpers and colleagues. Data for this analysis were obtained from a representative sample of ninth graders in Germany. Following recent developments in the methodology of taxometric analysis, we will use a new taxometric approach developed by Ruscio et al. (2018), the CCFI profile method. Rather than estimating a putative taxon base rate and using that estimate to generate the taxon comparative data, the CCFI profile method replicates the analysis with each base rate estimate between 0.025 and 0.975 in increments of 0.025 . 


\section{Method}

\section{Sampling Method}

The following analysis uses child-report data from ninth grade students in Germany originating from a periodically conducted representative survey (see Kliem et al., 2020), carried out by the Criminological Research Institute of Lower Saxony in spring 2015. The Ministry of Education of Lower Saxony (this constitutes the state's educational authority) approved the survey and provided ethics auditing. The survey was strictly anonymized - neither names, nor private or school addresses were obtained. The study was conducted in accordance with the World Medical Association's (WMA) Declaration of Helsinki. The survey was carried out by trained test administrators within a classroom setting and was completed in a time frame of two school lessons (90 min). The students' parents received an information leaflet beforehand, which included a request for written consent for the participation of their child and provided them with information about the institution conducting the study, as well as aims, methods and financing of the study. Furthermore, the students themselves could also independently refuse to participate, despite the existing consent given by their parents. Students were informed that their participation in the survey is entirely voluntary and anonymous and that they could withdraw their participation consent at any time without any negative consequences. Furthermore, they were informed of their right to skip individual questions within the survey and were encouraged to speak to a counsellor, school psychologist or an anonymous crisis hotline if they were to feel negatively affected by partaking in the survey. Of the $N=3,878$ students who participated, $51.4 \%$ are female ( $n=1,992$ individuals). The mean age is $M=14.9$ years $(S D=0.71)$, with an age range of 13 to 19 years. $N=926(23.9 \%)$ of the respondents have a migration background (i.e., students or at least one of their parents were not born in Germany or do not have German citizenship).

\section{Measures}

The Inventory of Callous-Unemotional Traits (ICU) by Frick (2004) can be considered the current standard for assessing CU traits (e. g. Cardinale \& Marsh, 2020; Frick \& Ray, 2015; Frick et al., 2014; Ray \& Frick, 2020). The ICU is based on four items of the CU scale of Frick and Hare's Antisocial Process Screening Device (APSD; Frick $\&$ Hare, 2001). These four original APSD items formed the basis of the four subscales Uncaring, Unemotional, Callous and Careless. These subscales correspond to the LPE dimensions of the DSM-5 (see Kimonis et al., 2015). A German version of the ICU (Frick, 2004; German version by Essau et al., 2006) was used to record childreported insensitive, insidious, and hard-hearted properties. On the ICU, the young people indicate how accurately each item describes their own behavior (from $0=$ "not at all true" to $3=$ "definitely true").

\section{Statistical Methods}

\section{Missing Values}

Missing values (all included items $<5 \%$ missing data) were estimated using Chained Equation Modelling (see White et al., 2011). To avoid the imputation of item values, which do not correspond to the possible characteristics of the items, estimated values are in turn replaced by the "nearest natural neighbor" (Predictive Mean Matching Method, Little, 1988). Imputation was carried out using the R package mice (Multivariate Imputation by Chained Equations in R; van Buuren \& Groothuis-Oudshoorn, 2011).

\section{Indicator Selection}

We tested two different three-indicator sets based on the work of Essau et al. (2006) [Uncaring (\#3, \#5, \#13, \#15, \#16, \#17, \#23, \#24), Unemotional (\#1, \#6, \#14, \#19, \#22) Callous (\#2,\#4, \#7, \#8, \#9, \#10, \#11,\#12, \#18, \#20,\#21)] and Kimonis et al. (2015) (excluding item \#2 and \#10). Furthermore, we analyzed two four-indicator sets on the original model of the APSD [Uncaring (\#4, \#8, \#12, \#17, \#21, \#24), Unemotional (\#1, \#6, \#10, \#14,\#19, \#22), Callous (\#2,\#5, $\# 9$, \#13, \#16, \#18), and Careless (\#3, \#7, \#11, \#15, \#20, $\# 23)]$ and the work of Kliem et al. (2020) (excluding item $\# 2$, \#10, and \#13).

\section{Taxometric Analysis}

As recommended by Ruscio et al. (2010), we applied three non-redundant taxometric procedures: Mean above minus below a cut (MAMBAC Meehl \& Yonce, 1994;), maximum eigenvalue (MAXEIG; Waller \& Meehl, 1998), and latentmode factor analysis (L-MODE; Waller \& Meehl, 1998). Following the suggestion by Ruscio et al., (2007; see Ruscio et al. (2011) for a comprehensive introduction), two comparison populations (each $N=100,000$ ) using (a) the categorical model and (b) the dimensional model were generated for each of the taxometric procedures. Relevant aspects of the empirical data, such as skewness, inter-correlations, and non-normality were held constant. In a second step, random samples $(K=100$; with the same sample size of the empirical data set) were drawn from both populations. The 
R package RTaxometrics by Ruscio and Wang (2017) was used for these simulations. All samples were then analyzed using the three different taxometric procedures (MAMBAC, MAXEIG, L-MODE).

The root-mean-square distance between empirical data points on curves and data points on simulated categorical (FitCat) as well as simulated dimensional (FitDim) reference curves were calculated (smaller values indicating that both curves resemble one another more closely). Next, the comparison curve fit index $(\mathrm{CCFI}=$ FitDim $/($ FitDim + FitCat $))$ was calculated for each taxometric procedure. In accordance with Ruscio et al. (2010), the mean CCFI of the MAMBAC, MAXEIG, and L-MODE procedure was used to interpret the latent status of $\mathrm{CU}$ traits. Rather than estimating a putative taxon base rate and using that estimate to generate the taxon comparative data, we used the CCFI profile method developed by Ruscio et al. (2018). This method replicates the analysis with each base rate estimate between $2.5 \%$ and $97.5 \%$ in increments of $2.5 \%$. If the construct is taxonic, the CCFI value should be greatest at the most accurate base rate estimation (Ruscio et al., 2018). In Monte Carlo simulations, this method provided a more accurate base rate estimation (in the case of categorical structure) as well as a particularly adequate estimate of latent structure on the basis of a CCFI profile value, whereby a CCFI profile value above 0.50 denotes a better fit for a categorical latent structure and a value below 0.50 denotes a better fit for a dimensional latent structure (Ruscio et al., 2018). We used Ruscio's and Wang's R package RTaxometrics (Ruscio \& Wang, 2017) for the analysis. We performed CCFI profile analyses for the total sample as well as for males and females separately.

\section{Suitability of Data for Taxometric Analysis}

To check the prerequisites for taxometric analysis, assigning cases to putative groups is necessary. Based on Ruscio's, Ruscio's, and Carney's recommendations, case classification should be based on a meaningful diagnostic algorithm or valid assessment tool. It should be noted that any of these classification procedures is necessarily based on the assumption of a categorical latent structure. If taxometric results indicate a dimensional structure, this classification must however be questioned. Also, the determined base rates (see below) should then not be interpreted further. We used a group variable (taxon vs. complement) based on an algorithm presented by Kimonis et al. (2015). Four CU items (\#3, \#5, \#6, and \#8) were dichotomized (coded as present if rated 3 "definitely true"; see Kimonis et al., 2015). The following two groups were formed: Those reporting no symptoms or one symptom (i.e., not meeting CU specifier criteria) and those reporting $\geq 2$ symptoms (i.e., meeting specifier criteria), reflecting the DSM-5 symptom threshold (APA, 2013). Based on this threshold, we found a base rate for the putative taxon group of $8.1 \%(\mathrm{n}=313)$ for the total sample, of $10.9 \%(n=205)$ for the male sample as well as of 5.4\% $(n=108)$ for the female sample, respectively. Taxometric analysis requires all standardized mean differences between the hypothetical categorical groups to be larger than Cohen's $d=1.25$. Furthermore, all indicators should correlate substantially with each other (mean $r>0.30$ ), but the correlation should be substantially smaller within the hypothetical categorical groups $\left(r_{w g} \leq 0.30\right)$ (Ruscio et al., 2011).

\section{Results}

\section{Taxometric Analyses of CU traits}

\section{Three-Indicator Sets}

The overwhelming majority of all standardized mean differences exceeded the required cut-off of $d=1.25$ (see Table 1). We observed an average correlation between $r=0.28$ and $r=0.35$ and smaller correlation coefficients in the hypothetical categorical groups (Essau et al., 2006: between $r=0.12$ and $r=0.16$ [taxon], between $r=0.24$ and $r=0.29$ [complement]; Kimonis et al. (2015): between $r=0.11$ and $r=0.17$ [taxon], between $r=0.25$ and $r=0.30$ [complement]). Figure 1 depicts the graphical taxometric results for the CCFI profile analyses of both three-indicator sets (Essau et al., 2006; Kimonis et al., 2015). Strong support for the superiority of a dimensional model was detected regarding the total sample (Essau et al.: CCFI mean profile $=0.316$; Kimonis et al.: CCFI mean profile $=0.316$ ), the male sample $($ CCFI mean profile $=0.328 / 0.376$ ), and the female sample (CCFI mean profile $=0.322 / 0.248$ ).

\section{Four-Indicator Sets}

The majority of all standardized mean differences exceeded the required cut-off of $d=1.25$ (see Table 1). We observed an average correlation between $r=0.39$ and $r=0.39$, and smaller correlations in the hypothetical categorical groups (APSD: between $r=0.25$ and $r=0.28$ [taxon], between $r=0.32$ and $r=0.35$ [complement]; Kliem et al., 2020: between $r=0.22$ to 0.25 [taxon], between $r=0.32$ and 0.35 [complement]). Figure 2 depicts the graphical taxometric results for the CCFI profile analyses of both four-indicator sets. Strong support for the superiority of a dimensional model was detected regarding the total sample (APSD: CCFI mean profile $=0.292$; Kliem et al., 2020: CCFI mean profile $=0.285)$, the male sample $($ CCFI mean profile $=0.313 / 0.318$ ), and the female sample (CCFI mean profile $=0.359 / 0.332$ ) 
Table 1 Results from the Taxometric Analysis

\begin{tabular}{|c|c|c|c|c|c|c|}
\hline Indicator selection & Sample & $\begin{array}{l}\text { Base rate / Size of the } \\
\text { potential taxon group }\end{array}$ & $d$ & Indicator correlation & CCFI profile & Interpretation \\
\hline \multirow[t]{3}{*}{$\begin{array}{l}\text { 3-Indicators (Essau } \\
\text { et al., 2006) }\end{array}$} & Full sample & $8.1 \% / n=313$ & $\begin{array}{l}M=1.16 \\
\text { Range }=0.86-1.64\end{array}$ & $\begin{array}{l}\text { Average: } 0.31 \\
\text { Taxon: } 0.12 \\
\text { Complement: } 0.27\end{array}$ & $\begin{array}{l}\text { MAXEIG }=0.320 \\
\text { MAMBAC }=0.355 \\
\text { L-MODE }=0.289 \\
M=0.316\end{array}$ & dimensional \\
\hline & Male Sample & $10.9 \% / n=205$ & $\begin{array}{l}M=1.03 \\
\text { Range }=0.70-1.64\end{array}$ & $\begin{array}{l}\text { Average: } 0.28 \\
\text { Taxon: } 0.12 \\
\text { Complement: } 0.24\end{array}$ & $\begin{array}{l}\text { MAXEIG }=0.395 \\
\text { MAMBAC }=0.273 \\
\text { L-MODE }=0.325 \\
M=0.328\end{array}$ & dimensional \\
\hline & Female Sample & $5.4 \% / n=108$ & $\begin{array}{l}M=1.32 \\
\text { Range }=1.07-1.50\end{array}$ & $\begin{array}{l}\text { Average: } 0.34 \\
\text { Taxon: } 0.16 \\
\text { Complement:0.29 }\end{array}$ & $\begin{array}{l}\text { MAXEIG }=0.245 \\
\text { MAMBAC }=0.425 \\
\mathrm{~L}-\mathrm{MODE}=0.245 \\
M=0.322\end{array}$ & dimensional \\
\hline \multirow[t]{3}{*}{$\begin{array}{l}\text { 3-Indicators (Kimonis } \\
\text { et al., 2015) }\end{array}$} & Full sample & $8.1 \% / n=313$ & $\begin{array}{l}M=1.22 \\
\text { Range }=0.86-1.64\end{array}$ & $\begin{array}{l}\text { Average: } 0.33 \\
\text { Taxon: } 0.11 \\
\text { Complement: } 0.28\end{array}$ & $\begin{array}{l}\text { MAXEIG }=0.320 \\
\text { MAMBAC }=0.355 \\
\text { L-MODE }=0.289 \\
M=0.316\end{array}$ & dimensional \\
\hline & Male Sample & $10.9 \% / n=205$ & $\begin{array}{l}M=1.10 \\
\text { Range }=0.76-1.64\end{array}$ & $\begin{array}{l}\text { Average: } 0.30 \\
\text { Taxon: } 0.11 \\
\text { Complement: } 0.25\end{array}$ & $\begin{array}{l}\text { MAXEIG }=0.397 \\
\text { MAMBAC }=0.412 \\
\text { L-MODE }=0.333 \\
M=0.376\end{array}$ & dimensional \\
\hline & Female Sample & $5.4 \% / n=108$ & $\begin{array}{l}M=1.36 \\
\text { Range }=1.07-152\end{array}$ & $\begin{array}{l}\text { Average: } 0.35 \\
\text { Taxon: } 0.17 \\
\text { Complement: } 0.30\end{array}$ & $\begin{array}{l}\text { MAXEIG }=0.228 \\
\text { MAMBAC }=0.261 \\
\text { L-MODE }=0.279 \\
M=0.248\end{array}$ & dimensional \\
\hline \multirow[t]{3}{*}{ 4-Indicators (APSD) } & Full sample & $8.1 \% / n=313$ & $\begin{array}{l}M=1.18 \\
\text { Range }=0.78-1.54\end{array}$ & $\begin{array}{l}\text { Average: } 0.39 \\
\text { Taxon: } 0.26 \\
\text { Complement: } 0.34\end{array}$ & $\begin{array}{l}\text { MAXEIG }=0.221 \\
\text { MAMBAC }=0.341 \\
\text { L-MODE }=0.333 \\
M=0.292\end{array}$ & dimensional \\
\hline & Male Sample & $10.9 \% / n=205$ & $\begin{array}{l}M=1.04 \\
\text { Range }=0.63-1.42\end{array}$ & $\begin{array}{l}\text { Average: } 0.37 \\
\text { Taxon: } 0.28 \\
\text { Complement: } 0.32\end{array}$ & $\begin{array}{l}\text { MAXEIG }=0.268 \\
\text { MAMBAC }=0.360 \\
\text { L-MODE }=0.348 \\
M=0.313\end{array}$ & dimensional \\
\hline & Female Sample & $5.4 \% / n=108$ & $\begin{array}{l}M=1.31 \\
\text { Range }=1.02-1.58\end{array}$ & $\begin{array}{l}\text { Average: } 0.39 \\
\text { Taxon: } 0.25 \\
\text { Complement: } 0.35\end{array}$ & $\begin{array}{l}\text { MAXEIG }=0.206 \\
\text { MAMBAC }=0.496 \\
\mathrm{~L}-\mathrm{MODE}=0.373 \\
M=0.359\end{array}$ & dimensional \\
\hline \multirow[t]{3}{*}{$\begin{array}{l}\text { 4-Indicators (Kliem } \\
\text { et al., 2020) }\end{array}$} & Full sample & $8.1 \% / n=313$ & $\begin{array}{l}M=1.24 \\
\text { Range }=0.86-1.54\end{array}$ & $\begin{array}{l}\text { Average: } 0.39 \\
\text { Taxon: } 0.25 \\
\text { Complement: } 0.34\end{array}$ & $\begin{array}{l}\text { MAXEIG }=0.171 \\
\text { MAMBAC }=0.301 \\
\text { L-MODE }=0.399 \\
M=0.285\end{array}$ & dimensional \\
\hline & Male Sample & $10.9 \% / n=205$ & $\begin{array}{l}M=1.12 \\
\text { Range }=0.76-1.42\end{array}$ & $\begin{array}{l}\text { Average: } 0.38 \\
\text { Taxon: } 0.28 \\
\text { Complement: } 0.32\end{array}$ & $\begin{array}{l}\text { MAXEIG }=0.261 \\
\text { MAMBAC }=0.355 \\
\text { L-MODE }=0.380 \\
M=0.318\end{array}$ & dimensional \\
\hline & Female Sample & $5.4 \% / n=108$ & $\begin{array}{l}M=1.37 \\
\text { Range }=1.07-1.58\end{array}$ & $\begin{array}{l}\text { Average: } 0.39 \\
\text { Taxon: } 0.22 \\
\text { Complement: } 0.35\end{array}$ & $\begin{array}{l}\text { MAXEIG }=0.201 \\
\text { MAMBAC }=0.421 \\
\mathrm{~L}-\mathrm{MODE}=0.365 \\
M=0.332\end{array}$ & dimensional \\
\hline
\end{tabular}

Please note that in practice a final conclusion has to be drawn based on the mean CCFI profile instead of relying only on single CCFI profile values (i.e., MAXEIG, MAMBAC, or L-MODE; see Ruscio et al., 2018). Since the individual taxometric techniques provide independent evidence for the latent structure (see Ruscio et al., 2010), a certain variability of single CCFI profile values is to be expected

$d$ Cohen's, CCFI profile comparison curve fit index based on the CCFI profile method, MAXEIG maximum eigenvalue, MAMBAC mean above minus below a cut, $L-M O D E$ latent-mode factor analysis 

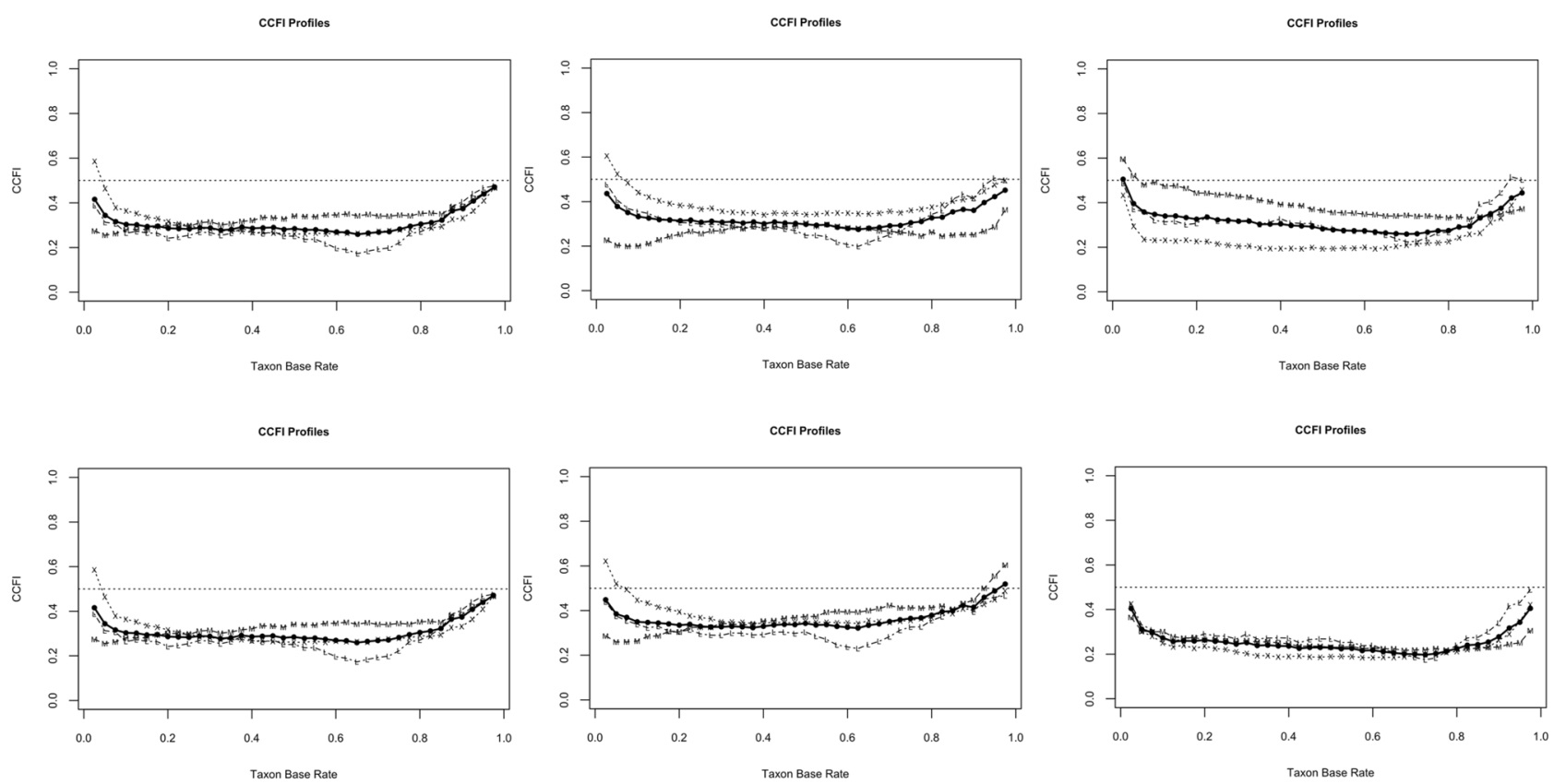

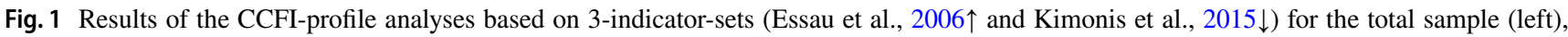
male sample (middle), and female sample (right)

\section{Discussion}

The present study evaluated the latent nature of CU traits in a large sample of German ninth graders. Results of different indicator sets clearly suggested a dimensional solution. This finding is consistent with previous studies showing the dimensionality of psychopathy in adolescents (Edens et al., 2011; Murrie et al., 2007; Walters, 2014) as well as of early disruptive behavior in preschoolers (Kliem et al., 2018). However, further studies are necessary to substantiate this result in different samples (especially in samples of adolescents with Conduct Disorder) using
CCFI Profiles

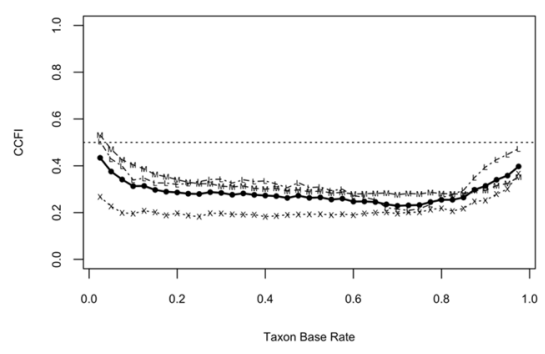

CCFI Profiles

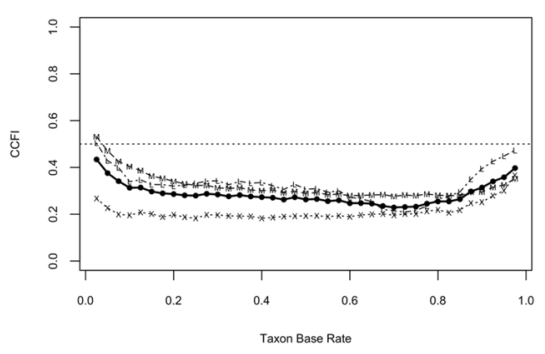

CCFI Profiles

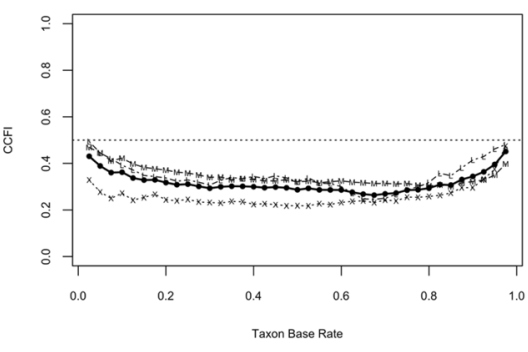

CCFI Profiles

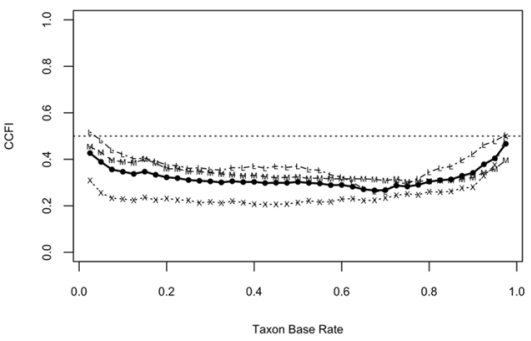

CCFI Profiles

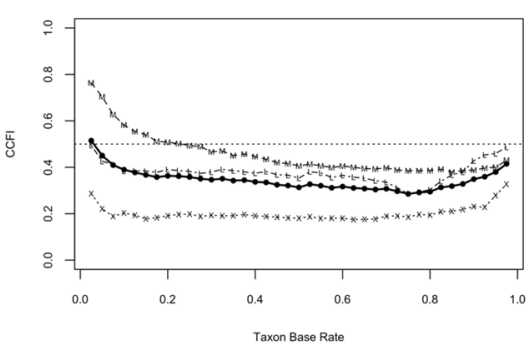

CCFI Profiles

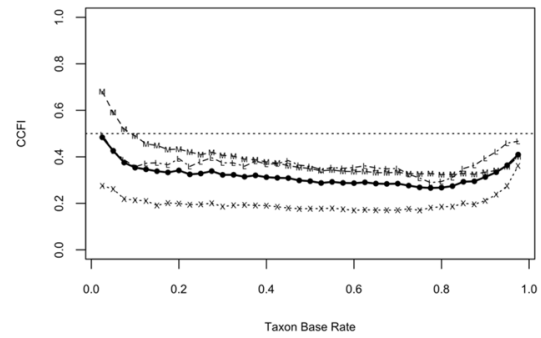

Fig. 2 Results of the CCFI-profile analyses based on 4-indicator-sets (APSD $\uparrow$ and Kliem et al., 2020 $\downarrow$ ) for the total sample (right), male sample (middle), and female sample (left) 
different measurement approaches (e.g., teacher reports, parent reports). However, a dimensional structure of $\mathrm{CU}$ traits has important theoretical and practical implications: First, results indicate that the process of classifying individuals in dichotomous groups ( $\mathrm{CU}+$ risk group) needs to be considered very carefully.

Second, it must be noted that people's perceptions are affected when a construct is communicated as categorical (e.g., Prentice \& Miller, 2007). For example, the term "highrisk group" implies that the condition is more enduring than a dimensional construct. Therefore, the present analysis should give reason for researchers to avoid labeling individuals in order to decrease the associated risk of stigmatization in both scientific communication and therapeutic contexts. Our finding appears to be of particular importance in the context of CU traits, since this clinical picture is generally associated with a poor prognosis (e.g., Frick \& White, 2008), a negative linguistic connotation with so-called "psychopathic traits" or "evil or dark personality" (Murrie et al., 2005), as well as treatment non-response (Falkenbach et al., 2003; Gretton et al., 2001; Hawes \& Dadds, 2005; Kolk \& Pardini, 2010; Masi et al., 2013; O'Neill et al., 2003; Spain et al., 2004; Waschbusch et al., 2007). Furthermore, labeling juveniles may also have a punishment-enhancing effect in legal settings, especially since the term 'psychopath' is associated with attributes such as cold-bloodedness, evilness, a pronounced lack of remorse and particularly high risk of recidivism (e.g., Berryessa, \& Wohlstetter, 2019; Petrila \& Skeem, 2003).

Third, for future research on CU traits, relevant implications can be drawn from the dimensionality of the construct. It seems particularly relevant that meaningful insights into the phenomenon can be derived from the study of subclinical samples. Furthermore, a dimensional structure suggests that a variety of risk factors affect the CU traits phenomenon (through addition and interaction). In this context, the polygenic nature of most psychiatric disorders should not be neglected, which are influenced by hundreds to thousands of genetic variations with very little (and interactive) effects (Moore et al., 2019).

\section{Limitations}

There are many strengths of this study, including the very large and representative sample. However, the study has some limitations. Firstly, self-reports were the only data source used, so it is possible that the results are subject to monomethod bias (e.g., Kliem et al., 2015, 2016). When attempting to replicate our findings in future studies, investigators should ensure that other data sources are used, such as other self-report-measures, teacher/parent reports, clinical interviews, and/or observational measures. Secondly, data presented here is limited to the age group of ninth graders with a mean age of 15 years. Although the data are considered suitable for taxonomic analysis, within-group indicator correlations lie above the threshold of $r=0.30$. According to Ruscio et al. (2006), difficulties in selecting appropriate indicators might itself be indirect evidence of dimensionality. ${ }^{1}$ According to Meehl (1995), a basis rate of $\geq 10 \%$ for the estimated taxon base rate (the proportion of taxon members in the sample) should be present. Our results fell below this value in some of the analyses. This is a limitation; however, it can also be pointed out that in the total sample the putative taxon group contains a very large number of cases $\left(N_{\text {taxon }}>300\right)$. It should be remembered that it is not only the base rate but also the absolute size of each group that determines the validity of a taxometric analysis. Furthermore, it may be noted that although the rate of ambiguous results for categorical data may increase slightly at base rates between 5 and $10 \%$, erroneous results (e.g., an incorrectly determined solution) are rarely generated (see Ruscio et al., 2011). Thus, based on the findings of our study, which very clearly support a dimensional structure, there appears to be a relatively low risk that a dimensional solution was erroneously determined.

\section{Conclusion}

In summary, the results of this study point to the need for critical reflection in defining a high-risk-group $(\mathrm{CU}+)$ in the context of CU traits. Although this classification may seem helpful to a clinician, it is possible that these classification systems impose clinical limitations that are not empirically defensible (see Haslam et al., 2006). With respect to the DSM-5 specifiers, the present results indicate that any classification into dichotomous groups needs to be considered very carefully. Furthermore, comparing prevalence rates across different groups (e.g., boys vs. girls, healthy vs. diseased, etc.) seems problematic. Indeed, the whole process of classifying individuals based on a sum score might be questionable (see Kliem et al., 2014).

Acknowledgements The school survey is funded by the Lower Saxony State Ministry of Science and Culture, Germany. No conditions were imposed with the financing. We thank all students who participated in the study, and the headmasters, teachers, and interviewers for helping us to carry out the study in the schools.

\footnotetext{
1 We have repeated the analyses with various indicator sets (i.e. forced three-, four and five-indicator sets using EFA-Promax/-Varimax, "best" (highest validity) items as indicators, "best" item pairs as indicators). All of these indicator sets showed similar properties regarding their amenability to the assumptions of the taxometric analysis. Irrespective of the indicator set analyzed, all results consistently pointed to a dimensional latent structure. Since, we regard the questionnaire used to be a valid operationalization of the construct at hand we consider these additional analyses to constitute sensitivity analyses corroborating our original conclusions.
} 
Funding Open Access funding enabled and organized by Projekt DEAL.

\section{Compliance with Ethical Standards}

Ethical Approval All procedures involving human participants were in accordance with the ethical standards of the institutional and/or national research committee, and with the 1964 Helsinki declaration and its later amendments or comparable ethical standards.

Informed Consent Informed Consent was obtained from each individual participating in the study and their parents or legal guardian.

Conflict of Interest No authors report any conflicts of interest associated with this study. The views and opinions expressed in this article are those of the authors only.

Open Access This article is licensed under a Creative Commons Attribution 4.0 International License, which permits use, sharing, adaptation, distribution and reproduction in any medium or format, as long as you give appropriate credit to the original author(s) and the source, provide a link to the Creative Commons licence, and indicate if changes were made. The images or other third party material in this article are included in the article's Creative Commons licence, unless indicated otherwise in a credit line to the material. If material is not included in the article's Creative Commons licence and your intended use is not permitted by statutory regulation or exceeds the permitted use, you will need to obtain permission directly from the copyright holder. To view a copy of this licence, visit http://creativecommons.org/licenses/by/4.0/.

\section{References}

American Psychiatric Association. (2013). Diagnostic and Statistical Manual of Mental Disorders (DSM-5®). American Psychiatric Pub.

Berryessa, C. M., \& Wohlstetter, B. (2019). The psychopathic "label" and effects on punishment outcomes: A meta-analysis. Law and Human Behavior, 43(1), 9-25. https://psycnet.apa.org/doi/10. 1037/lhb0000317

Blair, R. J. R., Leibenluft, E., \& Pine, D. S. (2014). Conduct disorder and callous-unemotional traits in youth. New England Journal of Medicine, 371(23), 2207-2216. https://doi.org/10.1056/NEJMra1315612

Cardinale, E. M., \& Marsh, A. A. (2020). The Reliability and Validity of the Inventory of Callous Unemotional Traits: A Meta-Analytic Review. Assessment, 27(1), 57-71. https://doi.org/10.1177/1073191117747392

Cecil, C. A., McCrory, E. J., Barker, E. D., Guiney, J., \& Viding, E. (2018). Characterising youth with callous-unemotional traits and concurrent anxiety: Evidence for a high-risk clinical group. European Child \& Adolescent Psychiatry, 27(7), 885-898. https://doi. org/10.1007/s00787-017-1086-8

de Wied, M., van Boxtel, A., Matthys, W., \& Meeus, W. (2012). Verbal, facial and autonomic responses to empathy-eliciting film clips by disruptive male adolescents with high versus low callous-unemotional traits. Journal of Abnormal Child Psychology, 40(2), 211-223. https:// doi.org/10.1007/s10802-011-9557-8

Edens, J. F., Marcus, D. K., \& Vaughn, M. G. (2011). Exploring the taxometric status of psy- chopathy among youthful offenders: Is there a juvenile psychopath taxon? Law and Human Behavior, 35(1), 13-24. https://doi.org/10.1007/s10979-010-9230-8

Essau, C. A., Sasagawa, S., \& Frick, P. J. (2006). Callous-unemotional traits in a community sample of adolescents. Assessment, 13(4), 454-469. https://doi.org/10.1177/1073191106287354
Falkenbach, D. M., Poythress, N. G., \& Heide, K. M. (2003). Psychopathic features in a juvenile diversion population: Reliability and predictive validity of two self-report measures. Behavioral Sciences and the Law, 21(6), 787-805. https://doi.org/10.1002/ bs 1.562

Frick, P. J. (2004). The Inventory of Callous-Unemotional Traits. University of New Orleans.

Frick, P. J., \& Hare, R. D. (2001). Antisocial Process Screening Device: APSD. Multi-Health Systems.

Frick, P. J., \& Ray, J. V. (2015). Evaluating callous-unemotional traits as a personality construct. Journal of Personality, 83(6), 710-722. https://doi.org/10.1111/jopy.12114

Frick, P. J., \& Viding, E. (2009). Antisocial behavior from a developmental psychopathology perspective. Development and Psychopathology, 21(Special Issue 04), 1111-1131. https://doi.org/ $10.1017 / \mathrm{S} 0954579409990071$

Frick, P. J., \& White, S. F. (2008). Research review: The importance of callous-unemotional traits for developmental models of aggressive and antisocial behavior. Journal of Child Psychology and Psychiatry, 49(4), 359-375. https://doi.org/10.1111/j. 1469-7610.2007.01862.x

Frick, P. J., Ray, J. V., Thornton, L. C., \& Kahn, R. E. (2014). Can callous-unemotional traits enhance the understanding, diagnosis, and treatment of serious conduct problems in children and adolescents? A Comprehensive Review. Psychological Bulletin, 140(1), 1-57. https://doi.org/10.1037/a0033076

Golden, R. R., \& Meehl, P. E. (1979). Detection of the schizoid taxon with MMPI indicators. Journal of Abnormal Psychology, 88(3), 217-233. https://doi.org/10.1037//0021-843x.88.3.217

Gretton, H. M., McBride, M., Hare, R. D., O’Shaughnessy, R., \& Kumka, G. (2001). Psychopathy and recidivism in adolescent sex offenders. Criminal Justice and Behavior, 28(4), 427-449. https://doi.org/10.1177/009385480102800403

Hare, R. D., \& Neumann, C. S. (2008). Psychopathy as a clinical and empirical construct. Annual Review of Clinical Psychology, 4(1), 217-246. https://doi.org/10.1146/annurev.clinpsy.3. 022806.091452

Haslam, N., McGrath, M. J., Viechtbauer, W., \& Kuppens, P. (2020). Dimensions over categories: A meta-analysis of taxometric research. Psychological Medicine, 50(9), 1418-1432. https:// doi.org/10.1017/S003329172000183X

Haslam, N., Williams, B., Prior, M., Haslam, R., Graetz, B., \& Sawyer, M. (2006). The latent structure of attention-deficit/hyperactivity disorder: A taxometric analysis. The Australian and New Zealand Journal of Psychiatry, 40(8), 639-647. https://doi.org/10.1080/j. 1440-1614.2006.01863.x

Hawes, D. J., \& Dadds, M. R. (2005). The treatment of conduct problems in children with callous-unemotional traits. Journal of Consulting and Clinical Psychology, 73(4), 737-741. https:// doi.org/10.1037/0022-006X.73.4.737

Herpers, P. C., Klip, H., Rommelse, N. N., Taylor, M. J., Greven, C. U., \& Buitelaar, J. K. (2017). Taxometric analyses and predictive accuracy of callous-unemotional traits regarding quality of life and behavior problems in non-conduct disorder diagnoses. Psychiatry Research, 253, 351-359. https://doi.org/10.1016/j. psychres.2017.04.004

Kimonis, E. R., Fanti, K. A., Frick, P. J., Moffitt, T. E., Essau, C., Bijttebier, P., \& Marsee, M. A. (2015). Using self-reported callous-unemotional traits to cross-nationally assess the DSM-5 'With Limited Prosocial Emotions' specifier. Journal of Child Psychology and Psychiatry, 56(11), 1249-1261. https://doi.org/10.1111/jcpp.12357

Kliem, S., Beller, J., Kröger, C., Birowicz, T., Zenger, M., \& Brähler, E. (2014). Dimensional latent structure of somatic symptom reporting in two representative population studies: Results from taxometric analyses. Psychological Assessment, 26(2), 484-492. https://doi.org/10.1037/a0035721 
Kliem, S., Foran, H. M., Beller, J., Hahlweg, K., Stöbel-Richter, Y., \& Brähler, E. (2015). Dimensional latent structure of relationship quality: Results of three representative population samples. Journal of Marriage and Family, 77(5), 1190-1201. https://doi. org/10.1111/jomf.12211

Kliem, S., Heinrichs, N., Lohmann, A., Bussing, R., Schwarzer, G., \& Briegel, W. (2018). Dimensional latent structure of early disruptive behavior disorders: A taxometric analysis in preschoolers. Journal of Abnormal Child Psychology, 46(7), 1385-1394. https://doi.org/10.1007/s10802-017-0383-5

Kliem, S., Kröger, C., Foran, H. M., Mößle, T., Glaesmer, H., Zenger, M., \& Brähler, E. (2016). Dimensional latent structure of PTSD-symptoms reporting: Is it adding by subtracting? Psychological Assessment, 28(12), 1663-1673. https://doi.org/10. 1037/pas0000287

Kliem, S., Lohmann, A., Neumann, M., Glaubitz, C., Haselbach, S., Bergmann, M. C., \& Baier, D. (2020). Factor structure of the inventory of callous-unemotional traits in a representative sample of German 9th grade students. Journal of Abnormal Child Psychology, 48(1), 43-55. https://doi.org/10.1007/ s10802-019-00590-x

Kolk, D. J., \& Pardini, D. A. (2010). ODD dimensions, ADHD, and callous-unemotional traits as predictors of treatment response in children with disruptive behavior disorders. Journal of Abnormal Psychology, 119(4), 713-725. https://doi.org/10. 1037/a0020910

Little, R. J. (1988). A test of missing completely at random for multivariate data with missing values. Journal of the American Statistical Association, 83(404), 1198-1202. https://doi.org/ $10.1080 / 01621459.1988 .10478722$

Masi, G., Muratori, P., Manfredi, A., Lenzi, F., Polidori, L., Ruglioni, L., \& Milone, A. (2013). Response to treatments in youth with disruptive behavior disorders. Comprehensive Psychiatry, 54(7), 1009-1015. https://doi.org/10.1016/j.comppsych.2013.04.007

McMahon, R. J., Witkiewitz, K., Kotler, J. S., \& The Conduct Problems Prevention Research Group. (2010). Predictive validity of callous-unemotional traits measured in early adolescence with respect to multiple antisocial outcomes. Journal of Abnormal Psychology, 119(4), 752-763. https://doi.org/10.1037/a0020796

Meehl, P. E. (1995). Bootstraps taxometrics: Solving the classification problem in psychopathology. American Psychologist, 50(4), 266-275. https://doi.org/10.1037/0003-066X.50.4.266

Meehl, P. E., \& Yonce, L. J. (1994). Taxometric analysis: I. Detecting taxonicity with two quantitative indicators using means above and below a sliding cut (MAMBAC procedure). Psychological Reports, 74, 1059-1274.

Moore, A. A., Blair, R. J., Hettema, J. M., \& Roberson-Nay, R. (2019). The genetic underpinnings of callous-unemotional traits: A systematic research review. Neuroscience \& Biobehavioral Reviews, 100, 85-97. https://doi.org/10.1016/j.neubiorev.2019.02.018

Murrie, D. C., Cornell, D. G., \& McCoy, W. K. (2005). Psychopathy, conduct disorder, and stigma: Does diagnostic labeling influence juvenile probation officer recommendations? Law and Human Behavior, 29(3), 323-342. https://doi.org/10.1007/ s10979-005-2415-x

Murrie, D. C., Marcus, D. K., Douglas, K. S., Lee, Z., Salekin, R. T., \& Vincent, G. (2007). Youth with psychopathy features are not a discrete class: A taxometric analysis. Journal of Child Psychology and Psychiatry, 48(7), 714-723. https://doi.org/10. 1111/j.1469-7610.2007.01734.x

O’Neill, M. L., Lidz, V., \& Heilbrun, K. (2003). Predictors and correlates of psychopathic characteristics in substance abusing adolescents. International Journal of Forensic Mental Health, 2(1), 35-45. https://doi.org/10.1080/14999013.2003.10471177
Petrila, J., \& Skeem, J. L. (2003). Juvenile psychopathy: The debate. Behavioral Sciences and the Law, 21(6), 689-694. https://doi. org/10.1002/bs1.569

Prentice, D. A., \& Miller, D. T. (2007). Psychological essentialism of human categories. Current Directions in Psychological Science, 16(4), 202-206. https://doi.org/10.1111/j.1467-8721. 2007.00504.x

Ray, J. V., \& Frick, P. J. (2020). Assessing Callous-Unemotional Traits Using the Total Score from the Inventory of CallousUnemotional Traits: A Meta-Analysis. Journal of Clinical Child \& Adolescent Psychology, 49(2), 190-199. https://doi.org/10. 1080/15374416.2018.1504297

Ruscio, J., \& Ruscio, A. M. (2004). Clarifying boundary issues in psychopathology: The role of taxometrics in a comprehensive program of structural research. Journal of Abnormal Psychology, 113(1), 24-38. https://doi.org/10.1037/0021-843X.113.1.24

Ruscio, J., \& Wang, S. B. (2017). RTaxometrics: Taxometric analysis. (R package version 2.3). https://CRAN.R-project.org/packageRTaxometrics

Ruscio, J., Carney, L. M., Dever, L., Pliskin, M., \& Wang, S. B. (2018). Using the comparison curve fix index (CCFI) in taxometric analyses: Averaging curves standard errors and CCFI profiles. Psychological Assessment, 30(6), 744-754. https://doi. org/10.1037/pas0000522

Ruscio, J., Haslam, N., \& Ruscio, A. M. (2006). Introduction to the Taxometric Method: A Practical Guide. Lawrence Erlbaum Associates.

Ruscio, J., Ruscio, A. M., \& Carney, L. M. (2011). Performing taxometric analysis to distinguish categorical and dimensional variables. Journal of Experimental Psychopathology, 2(2), 170-196. https://doi.org/10.5127/jep.010910

Ruscio, J., Ruscio, A. M., \& Meron, M. (2007). Applying the bootstrap to taxometric analysis: Generating empirical sampling distributions to help interpret results. Multivariate Behavioral Research, 42(2), 349-386. https://doi.org/10.1080/00273170701360795

Ruscio, J., Walters, G. D., Marcus, D. K., \& Kaczetow, W. (2010). Comparing the relative fit of categorical and dimensional latent variable models using consistency tests. Psychological Assessment, 22(1), 5-21. https://doi.org/10.1037/a0018259

Sebastian, C. L., McCrory, E. J., Cecil, C. A., Lockwood, P. L., De Brito, S. A., Fontaine, N. M., \& Viding, E. (2012). Neural responses to affective and cognitive theory of mind in children with conduct problems and varying levels of callous-unemotional traits. Archives of General Psychiatry, 69(8), 814-822. https:// doi.org/10.1001/archgenpsychiatry.2011.2070

Spain, S. E., Douglas, K. S., Poythress, N. G., \& Epstein, M. (2004). The relationship between psychopathic features violence and treatment outcome: The comparison of three youth measures of psychopathic features. Behavioral Sciences and the Law, 22(1), 85-102. https://doi.org/10.1002/bsl.576

van Buuren, S., \& Groothuis-Oudshoorn, K. (2011). Mice: Multivariate imputation by chained equations in R. Journal of Statistical Software, 45(3), 1-67. https://doi.org/10.18637/jss.v045.i03

Vasey, M. W., Kotov, R., Frick, P. J., \& Loney, B. R. (2005). The latent structure of psychopathy in youth: A taxometric investigation. Journal of Abnormal Child Psychology, 33(4), 411-429. https://doi.org/10.1007/s10802-005-5723-1

Waller, N. G., \& Meehl, P. E. (1998). Multivariate taxometric procedures: Distinguishing types from continua. Sage.

Walters, G. D. (2014). The latent structure of psychopathy in male adjudicated delinquents: A cross-domain taxometric analysis. Personality Disorders: Theory Research and Treatment, 5(4), 348-355. https://doi.org/10.1037/per0000088

Waschbusch, D. A., Carrey, N. J., Willoughby, M. T., King, S., \& Andrade, B. F. (2007). Effects of methylphenidate and behavior modification on the social and academic behavior of children with 
disruptive behavior disorders: The moderating role of callous/unemotional traits. Journal of Clinical Child and Adolescent Psychology, 36(4), 629-644. https://doi.org/10.1080/15374410701662766

White, I. R., Royston, P., \& Wood, A. M. (2011). Multiple imputation using chained equations: Issues and guidance for practice.
Statistics in Medicine, 30(4), 377-399. https://doi.org/10.1002/ $\operatorname{sim} .4067$

Publisher's Note Springer Nature remains neutral with regard to jurisdictional claims in published maps and institutional affiliations. 